\title{
CHLORIDE-DEPENDENT TRANSMURAL POTENTIAL IN THE RECTAL WALL OF SCHISTOCERCA GREGARIA
}

\author{
L. Herrera, R. Jordana, and F. Ponz \\ Department of Zoology and Department of Physiology, University of Navarra, Pamplona, Spain
}

(Received 8 fuly 1975)

\begin{abstract}
Abatract-Rectum transmural potential (PD) and short-circuit current $\left(I_{\mathrm{BC}}\right)$ of the desert locust, Schistocerca gregaria, have been studied in vitro, with everted rectal wall preparations in solutions of different ionic composition. Initially, a PD of about $35 \mathrm{mV}$ (lumen positive) and a $I_{\mathrm{ac}}$ of about $300 \mu \mathrm{A} \mathrm{cm}^{-2}$ were recorded. Omission of sodium or potassium (Tris as substitute), from the luminal side or from both sides led to an increase of 4 to $6 \mathrm{mV}$ in PD (lumen more positive) together with an increase in $I_{\mathrm{Bc}}$. In the absence of chloride alone (sulphate as substitute) the PD quickly dropped to nearly zero. In each case the control values were recovered on replacing the corresponding ions. Neither the PD nor the $I_{\mathrm{Bc}}$ changed when substitutions affected only the haemocoelic solution. These findings corroborate the assumption that active transport of chloride ions from lumen to haemolymph is the major factor for transmural PD and account for the short-circuit current in the rectal wall of desert locust. A working scheme is given to explain the influence of sodium, potassium, and chloride ions on the PD.
\end{abstract}

\section{INTRODUCTION}

THE FUNCTIONS of the rectal wall in the regulation of ions and water balance in insects have been extensively investigated (WIGGLESWORTH, 1953; Edney, 1957; Craig, 1960; Phillips, 1964a-c, 1965, 1970; MoRdue, 1969; Wall and Oschman, 1970; Prusch, 1974). The desert locust, Schistocerca gregaria, has received special attention. Experiments carried out in vivo (PHILLIPs, 1964a-c) revealed that water was reabsorbed from the lumen to the haemolymph against an osmotic gradient, where the luminal solutions reaching osmolarities two or three times higher than that of the haemolymph. Chloride, sodium, and potassium ions can also be transported against a concentration gradient. An electric potential difference (PD) of about $20 \mathrm{mV}$ between both sides of the rectal wall can be measured, the lumen being positive with respect to the haemolymph. As this PD was very insufficient to explain the developed $\mathrm{Na}^{+}$and $\mathrm{K}^{+}$gradients and as it opposes the transfer of $\mathrm{Cl}^{-}$to the haemolymph, mechanisms of active transport for these three ions were suggested. The resorption of these ions presented saturation phenomena, observed under adequate experimental conditions, and includes diffusion processes, with a permeability constant ten times higher for potassium than for sodium. Chloride permeability also appeared to be high. The morphological structure responsible for the transfer of water and ions was the large epithelial cells of the six longitudinal rectal pads. In spite of experimental technique limitations, PHILlips (1964b) also observed that the inside of the epithelial cells was negative to both haemolymph and lumen; the potassium concentration inside the cells was higher than in the haemolymph, and the concentrations of sodium and chloride lower.

According to these results, a hypothetical scheme was suggested (PHILlips, 1965) for the cellular organization of the transport mechanisms involved in rectal reabsorption in this species. This model assumed the existence of the usual pump for potassium-sodium exchange, an influx of chloride, and an outflux of hydrogen ions across the lumen membrane to neutralize the inward potassium transport. The transmural potential was explained as the algebraic addition of both transmembrane potentials at the lumen and haemolymph sides, largely determined by the correspondent diffusion potentials of potassium.

In more recent experiments in vitro (IRVINE and PHILlips, 1971) the active transport of sodium and the transfer of water against an osmotic gradient could be confirmed, though at a lower rate than in vivo. However, under these experimental conditions, an active transport for potassium or chloride was not observed. Water transfer was higher than expected from the net sodium transfer and persisted when the latter ceased by the action of some inhibitors.

The fact that the rectal lumen in locust is electrically positive to the haemocoel, is an uncommon situation, contrary to what happens in most animals (Schultz and CURran, 1968), insects included (Prusch, 1974). However, a similar observation has been made in some other cases, as in the rectum of Sialis lutaria (SHAw, 1955) and the midgut of Hyalophora cecropia (HARVEY and NEDERGARD, 1964). 
The experiments reported in this paper offer new data on the relation of some ions to the electrical potentials developed in the rectal wall of locusts. They have been performed in vitro, with everted rectal preparations allowing a good oxygenation and correct measurements of the PD and shortcircuit current strengths $\left(I_{\mathrm{Bc}}\right)$. The fundamental rôle of the active transport of chloride ions in the rectal wall functions is shown.

\section{MATERIALS AND METHODS}

Adult male and female specimens of the desert locust (Schistocerca gregaria), reared after GRY et al. (in litt.), were used. The initial eggs (oötheca) were kindly supplied by the Laboratoire de Zoologie-Entomologie, Institute National Agronomique, Paris-Grignon.

After $24 \mathrm{hr}$ fasting, the abdomen of decapitated animals was opened from the ventral side, the intestine dissected out, and the terminal gut detached and transferred to the standard solution at $0^{\circ} \mathrm{C}$ and thoroughly rinsed. With the help of a thin glass rod, the terminal intestine was everted, and the rectum ticd at both ends on two assembled cannula (Fig. 1). The luminal side, i.e. the outside, was kept in a chamber with $2 \mathrm{ml}$ standard solution, constantly stirred by oxygen bubbling. The inner haemocoelic side was filled with about $0.5 \mathrm{ml}$ of fluid. The whole preparation remained in a waterbath at $30 \pm 0 \cdot 1^{\circ} \mathrm{C}$.

The measurements of the electrical PD between the luminal and haemocoelic compartments were made with two $\mathrm{KCl}$-calomel half-cell electrodes (KENNARD, 1953; Hills and Yves, 1961) connected to an A-35 Amplifier Electrometer from W. H. Associates having a $5 \times 10^{\circ} \Omega$ input impedance, and to

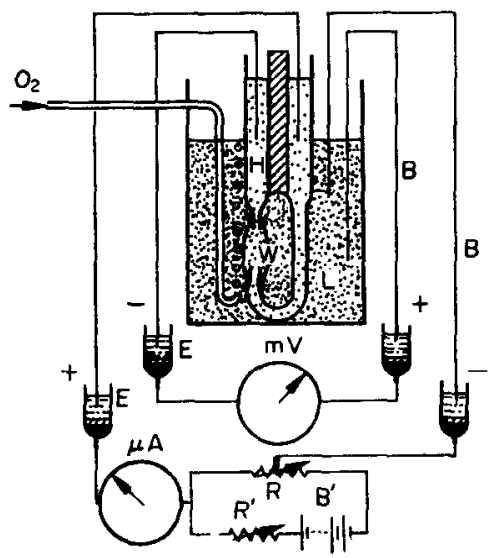

Fig. 1. Rectal chamber. Everted rectum (W); lumen side, close stippling (L); haemolymph side, sparse stippling $(\mathrm{H})$; inlet for stirring and oxygen bubbling $\left(\mathrm{O}_{2}\right)$; calomel electrodes (E); bridges between the bathing solutions and the calomel electrodes (B); potentiometer $(\mathrm{mV})$; dry-cell battery $\left(\mathrm{B}^{\prime}\right)$; microammeter $(\mu \mathrm{A})$; resistances $\left(R, R^{\prime}\right)$. a Harvard Apparatus Register Amplifier (Model 350) and Kimograph (Model 450).

The short-circuit current strength $\left(I_{\mathrm{sc}}\right)$ was also measured (Ussivg and ZERAFN, 1951) with calomel electrodes, using an electromotive force from a source of $45 \mathrm{~V}$, an appropriate variable resistance and a Model TS 160 Novotest microammeter.

The electrodes were connected through saline agar bridges prepared by filling narrow polyethylene tubes with $3 \%$ agar from the same solution used in the experiment.

The standard solution used for control experiments was that suggested for orthoptheran intestine by O'RIORDAN (1969) with the only exception that bicarbonate buffer was substituted by $0.5 \mathrm{mM}$ Tris-

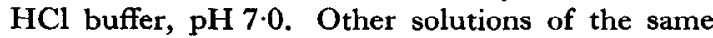
$\mathrm{pH}$ and osmolarity but lacking in sodium, potassium, or chloride were used, replacing the cations with Tris(Tris-hydroximethyl-amino-methane) and the anion with sulphate. Table 1 shows the composition of these different solutions.

To express $I_{\mathrm{sc}}$ and the current-flux equivalent (CFE) per area, the oversimplification that the surface of the rectal wall was that of a cylinder with the dimensions of the mean length and diameter of the rectum has been assumed.

The transmural PD along the experiments was continually recorded. The $I_{\mathrm{Bc}}$ needed to nullify the PD was measured at the beginning of the experiment ( 0 time) and at later times. From the $I_{\mathrm{sc}}$, the correspondent $\mathrm{CFE}$ value was calculated after the relation

$$
\begin{aligned}
1 \mu \mathrm{A} & =1 / 96.500 \mu \text {-equiv. } \text { seg }^{-1} \\
& =3.73 \times 10^{-2} \mu \text {-equiv. } \mathrm{h}^{-1} .
\end{aligned}
$$

The $\mathrm{pH}$ of solutions was measured with a PHM $52 \mathrm{~b}$ Radiometer $\mathrm{pH}$ meter.

\section{RESULTS}

In some experiments the preparations were maintained up to $45 \mathrm{~min}$ in the standard solution. In other experiments, they remained in standard solution for the first $18 \mathrm{~min}$; then, the bathing solution from both compartments was changed using another one without sodium, potassium or chloride; $10 \mathrm{~min}$ later, the standard solution was replaced. Every time the medium was changed, the preparation was quickly rinsed with the new solution. Measurements of the $I_{8 \mathrm{c}}$ both immediately before and after each change of medium were made.

In every experiment, the luminal side was found positive with respect to the haemocoelic one, with initial PD $(t=0)$ of about 30 to $40 \mathrm{mV}$. At this moment, the $I_{s c}$ was approximately $300 \mu \mathrm{A} \mathrm{cm}^{-2}$.

When the preparation was kept in the control (standard) medium, the PD and the $I_{\mathrm{Bc}}$ gradually declined (Fig. 2). This decline was taken into consideration for the interpretation of the other experiments. 
Table 1. Composition of bathing solutions. Standard (control) solution taken from O'Riordan (1969)

\begin{tabular}{|c|c|c|c|c|c|}
\hline \multirow{2}{*}{ Solution } & \multicolumn{5}{|c|}{ Compounds (miliMoles/litre) } \\
\hline & $\mathrm{NaCl}$ & $\mathrm{KCl}$ & $\mathrm{CaCl}_{2} \cdot 6 \mathrm{H}_{2} \mathrm{O}$ & $\mathrm{MgCl}_{2} \cdot 6 \mathrm{H}_{2} \mathrm{O}$ & Tris-HC1 \\
\hline Standard & 154.8 & 12.3 & 4.5 & 4.0 & $5.5-5.0$ \\
\hline Onission of $\mathrm{Na}^{+}$ & -- & 12.3 & 4.5 & 4.0 & $155.5-155.0$ \\
\hline Omission of $\mathrm{K}^{+}$ & 154.8 & - & 4.5 & 4.0 & $30.1-29.6$ \\
\hline Omission of $\mathrm{Cl}^{-*}$ & $110.8 \mathrm{Na}_{2} \mathrm{SO}_{4}$ & $9.2 \mathrm{~K}_{2} \mathrm{SO}_{4}$ & - & $\cdots$ & 5.5 Tris- $3 . \mathrm{HH}_{2} \mathrm{SO}_{4}$ \\
\hline
\end{tabular}

* This cliloride-free solution was also.r lacking in calcium and magnesium. Prelimirary experiments showed that omission of divalent cations during short periods had no effect on potentials.

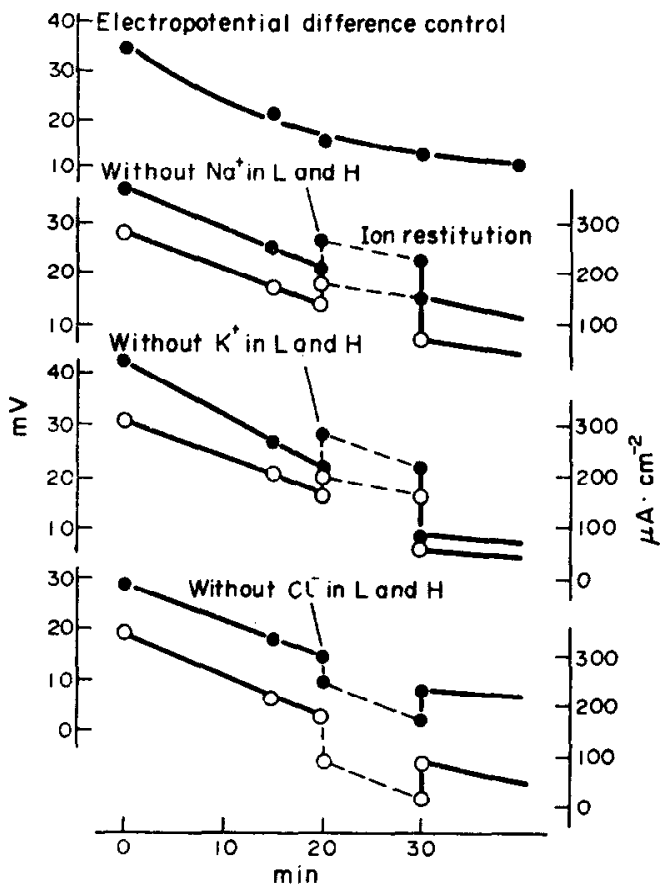

Fig. 2. Electropotential difference (PD) and shortcircuit current $\left(I_{\mathrm{Bc}}\right)$ across the rectal wall of locusts. Effects of omission and restitution of ions on both luminal $(\mathrm{L})$ and haemolymph $(\mathrm{H})$ sides., $\mathrm{PD} ; O, I_{\mathrm{gc}}$; - , control ; - ..-, ion omitted.

\section{Influence of the removal of cations on $\mathrm{PD}$ and $I_{\mathrm{BC}}$}

On changing from a standard to a $\mathrm{Na}^{+}$-free solution (Table 2, Fig. 2), a 5 to $6 \mathrm{mV}$ increase in PD was observed, the haemocoelic side being more negative. On returning a few minutes later to the standard solution, the PD dropped to the control values. The $I_{\mathrm{Bc}}$ shifted in conjunction with $\mathrm{PD}$ upon the change of the medium.

Similar results were seen, perhaps a little more pronounced, on substituting and replacing the potassium ions. In this case, when turning to the control solution after incubation in the absence of $\mathrm{K}^{+}$, the PD decreased to levels somewhat below those of the controls.
Since the substitute for $\mathrm{Na}^{+}$or $\mathrm{K}^{+}$in the corresponding solutions was Tris, and this substance does not diffuse across the cells, the changes in $I_{\mathrm{BC}}$ may be explained by an increase in the net transfer of diffusible anions from the luminal to the haemocoelic compartment, or to a decrease in the net movement of cations in the same direction. In both, the net flux of ions after suppression of $\mathrm{Na}^{+}$ or $\mathrm{K}^{+}$changes in 1 to $1.7 \mu$-equiv. $\mathrm{cm}^{-2} \mathrm{~h}^{-1}$, and that flux returns to the control values when the cation is again present in the medium, the difference being now about 3 to $4 \mu$-equiv. $\mathrm{cm}^{-2} \mathrm{~h}^{-1}$.

In some experiments, $\mathrm{Na}^{+}$and $\mathrm{K}^{+}$were simultaneously omitted in both compartments. The PD and $I_{\mathrm{BC}}$ changed in greater proportion but the effect did not prove to be additive.

\section{Influence of the removal of chloride on $\mathrm{PD}$ and $I_{\mathrm{sc}}$}

When the control solution was replaced by a chloride-free solution, substituting this anion by sulphate, the PD dropped nearly to zero in a very few minutes, and the $I_{\mathrm{sc}}$ dropped from $179 \mu \mathrm{A} \mathrm{\textrm {cm } ^ { - 2 }}$ to about 16 in less than 8 to $10 \mathrm{~min}$. Restoring the $\mathrm{Cl}^{-}$at that moment both $\mathrm{PD}$ and $I_{\mathrm{gc}}$ rapidly recovered their control values.

These striking effects produced by the omission of chloride from both compartments strongly points to this anion as the main cause of the transmural potential difference, so strictly dependent on the presence of chloride. In this assumption, the negativity of the haemocoelic compartment, when the rectal wall is incubated in control solution, can be explained by a net flux of chloride ions from the lumen to the haemocoel, which also determines the intensity of the opposite $I_{\mathrm{gc}}$. But when sulphate substitutes for chloride in both compartments, the anionic flux stops and the PD and the $I_{\mathrm{sc}}$ become practically zero since there are very few or no diffusible anions across the rectal wall.

\section{Unilateral vs. bilateral omission of ions}

To understand better the influence of monovalent ions on the electrical properties of the rectal wall, other experiments were carried out in which the 
Table 2. Electrical potential differences and short-circuit current strength across the rectal wall of locusts. Effects of omission of ions from both sides

\begin{tabular}{|c|c|c|c|c|c|c|c|c|c|}
\hline \multirow{3}{*}{\multicolumn{2}{|c|}{$\begin{array}{l}\text { Experimental } \\
\text { condtition } \\
\text { ton omited }\end{array}$}} & \multirow{3}{*}{$\begin{array}{l}\text { Para- } \\
\text { meters }\end{array}$} & \multicolumn{5}{|c|}{ Time (minutes) and solutions } & \multicolumn{2}{|c|}{ Changes \% } \\
\hline & & & \multicolumn{2}{|c|}{ Standard } & \multicolumn{2}{|c|}{ Ion omission } & \multirow{2}{*}{$\begin{array}{c}\text { Standa } \\
32\end{array}$} & \multirow{2}{*}{ Omission } & \multirow{2}{*}{ Restitutior } \\
\hline & & & 0 & 18 & 20 & 30 & & & \\
\hline \multirow[t]{2}{*}{$\mathrm{Na}^{+}$} & \multirow{2}{*}{ (12) } & CD & $37.0 \pm 5.2$ & 21.61 .2 .1 & $27.1 \pm 2.0$ & $22.9 \pm 2.0$ & $15.0 \pm 1.6$ & $+25.5^{*}$ & $-52.7^{x}$ \\
\hline & & Isc & $280.8 \pm 30.5$ & $146.6 \pm 13.2$ & $178.8 \pm 11.7$ & $159.1 \pm 6.6$ & $71.9 \pm 7.5$ & $+21.9 t$ & $-121.3^{x}$ \\
\hline & \multirow[b]{2}{*}{ (23) } & PD & $43.1 \pm .2 .6$ & $22.2 \pm 2.0$ & $29.1 \pm 1.9$. & $21.8 \pm 3.0$ & $7.9 \pm 1.4$ & $+31.1^{x x}$ & $-63.8^{x}$ \\
\hline & & Isc & $290.7 \pm 10.8$ & $161.7 \pm 14.3$ & $206.3 \pm 13.7$ & $168.5 \pm 15.5$ & $57.2 \pm 6.8$ & $+27.6^{x x}$ & $-114.6^{x}$ \\
\hline \multirow{2}{*}{$\mathrm{Cl}^{-}$} & & PD & $29.2 \pm 2.7$ & $15.4 \pm 1.9$ & $9.6 \pm 1.7$ & $2.6 \pm 0.5$ & $8.3 \pm 1.2$ & $-37.7^{*}$ & $+.68 .7^{x}$ \\
\hline & (14) & Isc & $341.3 \pm 25.9$ & $179.5 \pm 21.4$ & $92.0 \pm .12 .5$ & $16.1 \pm 3.3$ & $38.5 \pm 10.7$ & $-48.5^{x}$ & $+81.4^{x}$ \\
\hline
\end{tabular}

Statistical significance (Student's t test): $\mathrm{x}, \mathrm{P}<0.001 ; \mathrm{xx}, \mathrm{P}<0.01 ; *, \mathrm{P}<0.02 ; \dagger, \mathrm{P}<0.05$

Mean values $\pm S$.E. Potentials $(P D)$ in $m V$ (lumen always positive). Short-circuit current $\left(I_{\mathrm{ac}}\right)$ in $\mu \mathrm{A} \mathrm{cm}^{-2}$. Number of experiments in parentheses. Changes $\%:+$, increase; - , decrease.

ions were substituted only in one compartment. The standard solution in the luminal or haemocoelic compartment was changed after an incubation of $15 \mathrm{~min}$ by another solution without $\mathrm{Na}^{+}$, $\mathrm{K}^{+}$, or $\mathrm{Cl}^{-}$. Five min later the control solution was replaced (Table 3). The omission of each one of these ions from the haemocoelic compartment did not significantly affect the PD. The potential did not change either when Tris substituted $\mathrm{Na}^{+}$ in the lumen, but the $I_{\mathrm{Bc}}$ appreciably decreased on restoring it. However, the absence of $\mathrm{K}^{+}$or $\mathrm{Cl}^{-}$ in the luminal side produced very similar results to those described when the ions were absent from both compartments (Fig. 3) : suppression of potassium increased the haemocoelic negativity and the $I_{\mathrm{B}_{\mathrm{c}}}$, these values returning to normal when the cation was restored; the lack of chloride in the luminal compartment caused the drop of the haemocoelic negativity down to the loss of the electrical PD nullifying therefore the $I_{\mathrm{sc}}$, an effect which was reverted on restoring the control solution.

\section{DISCUSSION}

Performance of the in vitro preparation

The rectum of the locust $S$. gregaria, when kept

Table 3. Electrical potential differences and short-circuit current strength across the rectal wall of locusts. Effects of omission of ions from only one side

\begin{tabular}{|c|c|c|c|c|c|c|c|c|c|}
\hline \multirow{3}{*}{$\begin{array}{l}\text { Experimental } \\
\text { condition } \\
\text { Ion onteted }\end{array}$} & \multirow{3}{*}{$\begin{array}{l}\text { para- } \\
\text { meters }\end{array}$} & \multicolumn{6}{|c|}{ Tines (minuces) and solutions } & \multicolumn{2}{|c|}{ Changes ${ }_{i}$} \\
\hline & & \multicolumn{3}{|c|}{ Standard } & \multicolumn{2}{|c|}{ Ion Onission } & \multirow{2}{*}{$\begin{array}{l}\text { Standard } \\
22\end{array}$} & \multirow[t]{2}{*}{ Omission } & \multirow[t]{2}{*}{ Restitution } \\
\hline & & & 0 & 13 & 15 & 20 & & & \\
\hline $\mathrm{Na}^{+}$-free in $\mathrm{H}$ & PD & 28.4 & \pm 4.3 & $23.8 \pm 4.1$ & $20.3 \pm 3.7$ & $17.5 \pm 3.4$ & $18.8 \pm 3.4$ & $-14.7^{\circ}$ & $\div 6.9^{\circ}$ \\
\hline$(12)$ & Isc & 210.9 & \pm 19.2 & $132.1 \pm 26.9$ & $122.1 \pm 18.3$ & $107.3 \pm 17.3$ & $105.7 \pm 16.4$ & $+7.7^{\circ}$ & $-1.5^{\circ}$ \\
\hline $\mathrm{Na}^{+}$-free in.L & PD & 41.7 & \pm 2.9 & $28.8 \pm 3.2$ & $26.1 \pm 2.5$ & $22.6 \pm 2.3$ & $20.5 \pm 2.3$ & $=9.4^{\circ}$ & $-10^{\prime} .2^{\circ}$ \\
\hline$(10)$ & Ise & 286.7 & \pm 11.3 & $205.6 \pm 14.8$ & $203.0 \pm 12.3$ & $188.4 \pm 11.5$ & $154.9 \pm 12.7$ & $-1.0^{\circ}$ & $-21.6^{\circ}$ \\
\hline$x^{+}$-Eree $\ln H$ & PD & 34.1 & \pm 2.4 & $25.4 \pm 4.4$ & $20.9 \pm 4.7$ & $16.4 \pm 4.2$ & $17.5 \pm 4.7$ & $-17.7^{\circ}$ & $+6.3^{\circ}$ \\
\hline (6) & Isc & 238.5 & \pm 18.7 & $122.3 \pm 7.9$ & $104.2 \pm 11.7$ & $81.8 \pm 11.5$ & $88.8 \pm 10.8$ & $-16.0^{\circ}$ & $+7.8^{\circ}$ \\
\hline $\mathrm{K}^{+}$-free in $\mathrm{L}$ & PD & 29.7 & \pm 4.4 & $22.1 \pm 5.3$ & $30.2 \pm 4.5$ & $23.0 \pm 4.5$ & $14.5 \pm 3.6$ & +36.6 & $-36.9^{t}$ \\
\hline (8) & Isc & 182.3 & \pm 10.1 & $98.6 \pm 7.1$ & $128.8 \pm 9.8$ & $97.9 \pm 12.5$ & $50.1 \pm 11.3$ & +30.4 & $-95.2^{x x}$ \\
\hline $\mathrm{Cl}^{-}$-free in $\mathrm{H}$ & $\mathrm{PD}$ & 29.1 & \pm 2.7 & $22.4 \pm 2.8$ & $24.6 \pm \pm .3 .0$ & $22.3 \pm 2.8$ & $14.8 \pm 2.5$ & $+9.8^{\circ}$ & -50.7 \\
\hline (9) & Isc & 309.3 & \pm 17.1 & $244.0 \pm 20.8$ & $208.3 \pm 18.0$ & $197.5 \pm 45.3$ & $146.2 \pm 12.0$ & $-14.6^{\circ}$ & -35.2 \\
\hline $01^{-}$-free in $t$ & $P D$ & 30.8 & \pm 3.9 & $23.8+4.4$ & $18.7 \pm 4.1$ & $2.4 \pm 1.5$ & $11.4 \pm 2.7$ & -21.4 & $+78.9^{x}$ \\
\hline (11) & Isc & 252.0 & \pm 15.8 & $185.1 \pm 23.3$ & $100.4 \pm 18.0$ & $16.1 \pm 7.2$ & $77.9 \pm 15.1$ & $-45.8^{x}$ & $+79.1^{x}$ \\
\hline
\end{tabular}

According to the experiments, the omission was from the luminal side (I) or from the haemolymph side $(\mathrm{H})$, as indicated. Units and conditions as in Table 2. 
as an everted preparation incubated in vitro in the control solution, seems to be under good experimental conditions and receiving adequate oxygenation. A transmural difference of electrical potential develops (lumen positive with respect to haemocoel). The PD declines along the experiment (45 min) from an initial value of about $35 \mathrm{mV}$ to a final one of $12 \mathrm{mV}$. A similar but not so pronounced decrease of the transmural PD throughout the experimental time has been observed in Hyalophora cecropia (HARVEY and NEDERGARD, 1964). This spontaneous decline has not been an obstacle to obtain valuable and comparative results.

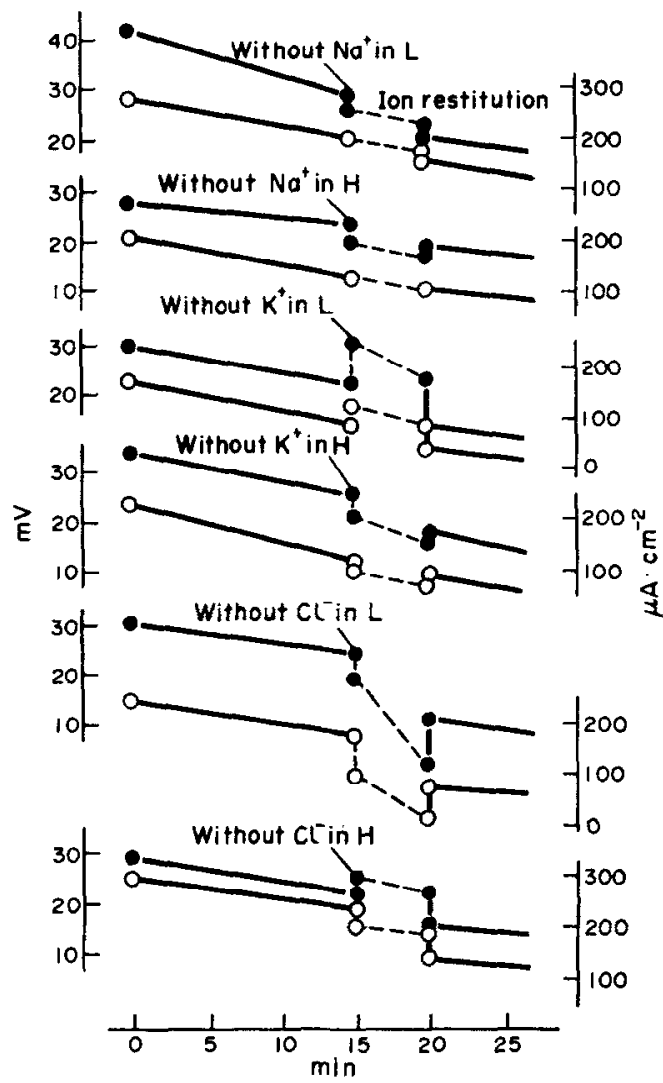

Fig. 3. Electropotential difference (PD) and shortcircuit current $\left(I_{\mathrm{sc}}\right)$ across the rectal wall of locusts. Effects of omission and restitution of ions on the luminal (L) or haemolymph (H) side. $\mathrm{O}, \mathrm{PD} ; \mathrm{O}, I_{\mathrm{sc}}$; control; - - - , ion omitted.

The mean value of the $\mathrm{PD}$, measured at the beginning of the experiments, is higher than that found in the locust in vivo by PHILlips (1964b). The $I_{\mathrm{sc}}$ at that moment is high relatively, amounting to about $300 \mu \mathrm{A} \mathrm{cm}^{-2}$, the CFE being $12 \mu$-equiv. $\mathrm{cm}^{-2} \mathrm{~h}^{-1}$, in terms of a net flux of anions from the lumen to the haemocoel.

The transmural potential of the rectal wall, obviously dependent on ionic fluxes, can be expressed as the algebraic sum of the two transmembrane potentials developed at the luminal and haemocoelic surfaces of the epithelial cells. Measurements of these transmembrane potentials have not yet been made in vitro, but the values measured in vivo (PrILlIPs, 1964b), even if subjected to experimental restrictions, revealed that the interior of the cells was negative with respect to the exterior, the haemocoelic side being less positive than the rectal lumen.

\section{Omission of sodium, potassium, or chloride ions}

The fact that suppression of sodium or potassium from both compartments, using the non-penetrating cation Tris as substitute, did not diminish but on the contrary increased the transmural potential, discards these cations as the principal determinants of this PD. Moreover, the lack of effect when Tris substitutes $\mathrm{Na}^{+}$or $\mathrm{K}^{+}$on the haemocoelic side excludes the short-circuit current as a measure of a net flux of cations from the haemocoel to the rectal lumen. A possible explanation could be to consider, as the main electrogenic factor, the net transfer of anions from lumen to haemocoel or the exit of hydrogen ions from cell to lumen coupled to that of some anion, perhaps $\mathrm{CO}_{3} \mathrm{H}^{-}$, from cell to haemocoel.

The effects produced by substituting the nonpenetrating anion sulphate for chloride in the bathing solution are very significant. When chloride is missing on both sides, the PD falls and disappears in a few minutes, and the $I_{8 C}$ is correspondingly nullified. When chloride is restored, the PD and the $I_{80}$ values quickly recover. These dramatic effects corroborate the hypothesis that transmural potentials are mainly dependent on chloride fluxes, and the $I_{B O}$ actually reflects a net flux of chloride ions from the lumen to the haemolymph. This flux would be the basic determinant for the negativity of the haemocoelic side with respect to the lumen. These conclusions are strengthened by the fact that chloride omission in the haemocoelic side has no consequences on the transmural PD, whereas the PD and the $I_{\mathrm{BC}}$ are reduced almost to zero when chloride is missing in the lumen.

\section{The flux of chloride as a major factor}

The possibility of a secretion of hydrogen ions is supported by the acidification of the rectal lumen observed in in vivo experiments (PHILLIPS, 1961, 1965). However, the experiments in vitro presented in this paper were carried out with buffered solutions, where the $\mathrm{H}^{+}$exit was hardly able to produce any electrogenic effect. Moreover, in some experiments the buffer was omitted with a consequent decrease of the luminal $\mathrm{pH}$; it shifted from 6.523 to 5.853 , equivalent to a net flux of $\mathrm{H}^{+}$of about $0.024 \mu$-equiv. $\mathrm{cm}^{-2} \mathrm{~h}^{-1}$, too low to justify the PD and the high $I_{\mathrm{sc}}$ observed. Finally, the substantial fall of these two parameters by the lack 
of chloride in the medium cannot be understood if the $\mathrm{H}^{+}$secretion is the mean electrogenic factor.

The most plausible interpretation for these findings is to assume that an active transport of chloride takes place from lumen to haemocoel actoss the epithelial cells, this being the major electrogenic factor creating the transmural $P D$ with positivity in lumen and accounting for the strength of the short-circuit current. When $\mathrm{Na}^{+}$and $\mathrm{K}^{+}$are present in the medium, the active or passive flux of these cations, in the same direction as chloride, partially counteracts both $\mathrm{PD}$ and $I_{\text {ace }}$. For this reason, when sodium, potassium, or both, were omitted from the lumen side, using Tris as a substitute, an increase of these parameters was produced. This change, however, was not observed when the omission affected only the haemocoelic side.

\section{$A$ model for the rectal functions relating electrical potentials to ion fluxes}

The available data are not yet sufficient to present a satisfactory model to account for the bioelectrical potentials developed in the rectal wall of the desert locust. The following tentative scheme (Fig. 4) may be suggested while expecting future measurements of the intracellular ionic concentrations and the transmembrane potentials.

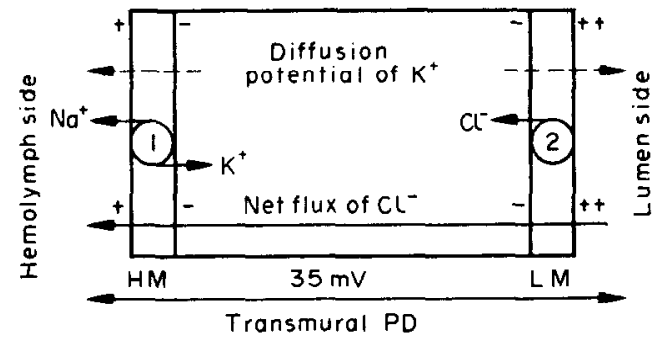

Fig. 4. A hypothetical scheme to explain transmural electrical potential differences in the rectal wall of $S$. gregaria. 1, Na-K pump; 2, chloride pump. LM and HM, Lumen and haemolymph membranes.

At the luminal membrane, chloride ions enter into the epithelial cells by active transport against an electrochemical potential gradient. These anions will then diffuse across the opposite membrane towards the haemocoel, rejected by the high level of negativity created by the non-diffusible intracellular anions. The resulting net flux of chloride from lumen to haemocoel favours the transfer of $\mathrm{K}^{+}$ and $\mathrm{Na}^{+}$in the same direction. A conventional pump for $\mathrm{Na}^{+}$and $\mathrm{K}^{+}$, which is probably placed on the haemocoelic membrane, sustains a high concentration of $\mathrm{K}^{+}$and a low one of $\mathrm{Na}^{+}$inside the cells. Sodium and potassium can also diffuse to the interior and the exterior of the cells across the luminal and haemocoelic membranes, generating the corresponding diffusion potentials. Since potassium permeability is much higher than that of $\mathrm{Na}^{+}$, as in the nerve fibre, the diffusion potentials of potassium are the most important factors for electronegativity at the inner side of membranes.

Usually, with chloride, sodium, and potassium in the medium on both sides of the rectal wall, the electrogenic character of the influx of chloride by pumping at the luminal membrane is here added to the diffusion potential of potassium. The opposite takes place at the haemocoelic membrane, where the outflux of chloride diminishes the diffusion potential of potassium. Therefore, the luminal compartment will be more positive than the haemocoelic one with respect to the inside of the cell, and the potential difference between both compartments (lumen positive) can be understood. This transmural potential will be, as it has been proved, essentially dependent on the movement of chloride ions from the lumen to haemocoel.

The net flux of $\mathrm{Na}^{+}$and $\mathrm{K}^{+}$from lumen to haemocoel against an electrochemical gradient can be ascribed to the combined action of the cationic pump and the active transport of chloride in the same direction.

According to this model, when $\mathrm{K}^{+}$is omitted from the bathing solution the diffusion potential of potassium on both membranes will increase. This increase will be higher at the luminal side due to the lack of influx of $\mathrm{K}^{+}$, resulting in an enhancement of transmural potential. However, when $\mathrm{K}^{+}$ is omitted only in the haemocoelic side, the transmural potential will not change.

The absence of $\mathrm{Na}^{+}$in the luminal or in both compartments also diminishes the movement of positive ions, forced by the pumping of chloride across the luminal membrane, resulting in an increase in the lumen positivity and in the transmural potential. The change is higher when the potassium is omitted because of greater permeability of the membrane to this ion.

The omission of chloride in the lumen or in both compartments will lead to the extinction of the active transport of this anion, with the disappearance of the main mechanism generating electrical asymmetry between haemocoelic and luminal membranes. As a consequence, transmural potential will drop rapidly.

With regard to the location of the $\mathrm{Na}^{+}-\mathrm{K}^{+}$pump, in vitro experiments (STOBART, 1968; IRVINE and Phillips, 1971) showed that ouabain, added to the haemocoelic side, inhibits the reabsorption of $\mathrm{Na}^{+}$, $\mathrm{K}^{+}, \mathrm{Cl}^{-}$, and water from the rectal lumen. This suggests that the pump is in the haemocoelic membrane.

Acknowledgement-This work was supported by grants from the Spanish 'Ministerio de Educación y Ciencia'.

\section{REFERENCES}

Craig R. (1960) The physiology of excretion in the insect. A. Rev. Ent. 5, 53-68. 
EDNEy E. B. (1957) The Water of Terrestrial Arthropods. Cambridge University Press, Cambridge.

Harvey W. R. and NeDErgard S. (1964) Sodium-independent active transport of potassium in the isolated midgut of the Cecropia silkworm. Proc, nat. Acad. Sci. U.S.A. 51, 757-765.

HrLls G. J. and Ives D. J. (1961) The calomel electrode and other mercury-mercurous salt electrodes. In Reference Electrodes, Theory and Practice (Ed. by Ives D. G. and Janz G. J.). Academic Press, New York.

Irvine H. B. and Phillips J. E. (1971) Effects of respiratory inhibitors and ouabain on water transport by isolated locust rectum. F. Insect Physiol. 17, 381383.

KENNARD D. W. (1953) Some modifications of silversilver chloride electrodes. F. Physiol. 120, 38P-39P.

Mordue W. (1969) Hormonal control of Malpighian tube and rectal function in the desert locust Schistocerca gregaria. F. Insect Physiol. 15, 273-285.

O'RIORDAN A. M. (1969) Electrolyte movement in the isolated midgut of the cockroach (Periplaneta americana L.). F. exp. Biol. 51, 699-714.

Phir.r.IPs J. E. (1961) Ph.D. Thesis, Cambridge University.

Phillips J. E. (1964a) Rectal absorption in the desert locust, Schistocerca gregaria Forsk.-I. Water. J.exp. Biol. 41, 15-38.

Phillips J. E. (1964b) Rectal absorption in the desert locust, Schistocerca gregaria Forsk.-II. Sodium, potassium and chloride. f. exp. Biol. 41, 39-67.
Prullips J. E. (1964c) Rectal absorption in the desert locust, Schistocerca gregaria Forsk.-III. The nature of the excretory process. F. exp. Biol. 41, 69-80.

Phillips J. E. (1965) Rectal absorption and renal function in insects. Trans. R. Soc. Can. 3, 237-254.

Prusch R. D. (1974) Active ion transport in the larval hindgut of Sarcophaga bullata (Diptera: Sarcophagidae). F. exp. Biol. 61, 95-109.

Schultz S. G. and Curran P. F. (1968) Intestinal absorption of sodium chloride and water. In Handbook of Physiology (Ed. by Am. Physiol. Soc.) 3(6), 12451275. Washington.

SHAw J. (1955) Ionic regulation and water balance in the aquatic larva of Sialis lutaria. 7. exp. Biol. 32, 353-382.

STOBBART R. H. (1968) Ion movements and water transport in the rectum of the locust Schistocerca gregaria F. Insect Physial. 14, 269-275.

Ussing H. H. and Zerahn K. (1951) Active transport of sodium as the source of electric current in the shortcircuited isolated frog skin. Acta physiol. Scand. 23, 110-127.

WaLL J. and Oschman J. L. (1970) Water and solute uptake by rectal pads of Periplaneta americana. Am. f. Physiol. 218, 1208-1215.

Wigglesworth V. B. (1967) Principles of Insect Physio$\log y, 6$ th ed. Methuen, London. 